\title{
Deep Venous Thrombosis: Commonly Affected Veins in the Lower Limbs
}

\author{
Sultan Abdulwadoud Alshoabi ${ }^{*}$, Abdullatif Mothanna ${ }^{2}$ \\ ${ }^{1}$ Department of Diagnostic Radiologic Technology, College of Applied Medical Sciences, Taibah University, \\ Al Madinah Alunawwarah, Saudi Arabia \\ ${ }^{2}$ Ibb Scan Medical Diagnostic Center, Ibb City, Republic of Yemen \\ Email: *alshoabisultan@yahoo.com
}

How to cite this paper: Alshoabi, S.A. and Mothanna, A. (2019) Deep Venous Thrombosis: Commonly Affected Veins in the Lower Limbs. Journal of Biosciences and Medicines, 7, 12-19.

https://doi.org/10.4236/jbm.2019.73002

Received: January 21, 2019

Accepted: March 1, 2019

Published: March 4, 2019

Copyright $\odot 2019$ by author(s) and Scientific Research Publishing Inc. This work is licensed under the Creative Commons Attribution International License (CC BY 4.0).

http://creativecommons.org/licenses/by/4.0/

\begin{abstract}
Aim and Objectives: This study aimed to record the commonly affected veins in the lower limbs, to compare the affected sides and gender and to correlate the Doppler findings and stages of deep venous thrombosis (DVT). Materials and Methods: A descriptive retrospective study of 46 already diagnosed cases of lower limb DVT. Results: Out of 46 cases of DVT, 71.74\% were females. The majority of patients (93.47\%) were affected in unilateral lower limb with significant predominance $(65.22 \%)$ to affect the left lower limb ( $\mathrm{p}<0.001)$. The common femoral vein (CFV) was affected in $71.7 \%$ of cases. The superficial femoral vein (SFV) was affected in $71.7 \%$ of cases. The popliteal vein was affected in $67.4 \%$. The deep femoral vein was affected only in $17.4 \%$. Both CFV and SFV were affected together in $47.8 \%$ of cases. Both SFV and popliteal vein were affected together in $50 \%$ of cases. The majority of DVT cases $(71.1 \%)$ were in the acute stage. This study revealed an essential relationship between the acute stage of DVT and distension of the affected veins ( $\mathrm{p}<0.001$ ) (OR 20.667, 95\% CI 3.826 - 111.633). It also detected a significant relationship between the acute stage and absence of venous blood flow ( $\mathrm{p}<0.001)($ OR 90.667, 95\% CI 8.303 - 990.114). Conclusion: Lower limb deep venous thrombosis affects left lower limb more than right and females more than males. Superficial femoral vein (SFV) and common femoral vein (CFV) are the most common affected veins. Lower limb DVT predominantly present in acute stage with venous distension and absent blood flow.
\end{abstract}

\section{Keywords}

Common Locations, Deep Venous Thrombosis (DVT), Lower Limbs

\section{Introduction}

Deep venous thrombosis (DVT) is the formation of blood clot within the deep 
veins of a living person. It frequently occurs in the lower limbs. It is a bad vascular problem that can result in a significant disability due to the post-thrombotic syndrome or death due to pulmonary embolism [1]. DVT affects nearly $1-2$ per 1000 of persons annually with predominance in elderly. The incidence increases with increasing age and patients on hospital admission [2]. Thrombophilic disorders, long period of immobilization, family history, chronic venous insufficiency, post-surgery conditions, hospitalization, active cancer, and hormone therapy such as oral contraceptive pills (OCPs), drugs that simulate hematopoiesis and obesity are common risk factors [3].

Imaging can establish the diagnosis of acute DVT. Ultrasonography is a non-invasive imaging modality to diagnosis of lower limb DVT. Bedside ultrasonography for lower limb DVT can be done by well-trained emergency physicians with $95 \%$ and $96 \%$ sensitivity and specificity respectively [4]. In 2016, the Society of Radiologists in Ultrasound Consensus Conference, recommended the protocol of ultrasound for lower limb DVT. The panel recommended a comprehensive duplex ultrasound protocol from the thigh to the ankle with Doppler at selected sites [5]. In a previous study for diagnosis of lower limb DVT in by emergency physicians by using the point of care compression ultrasound (POCUS), the sensitivity of three-point compression ultrasound (3PCUS) and two-point compression ultrasound (2PCUS) were $90.57 \%$ and $82.76 \%$ respectively but the specificity was $98.52 \%$ in both [6].

Doctors play an important role in reducing the incidence of DVT in high-risk patients such as pregnant women, and users of contraceptive pills, and in postoperative patients. The essential role of doctors lies in reducing the prevalence of DVT in high-risk patients and reducing complications by early diagnosis and treatment of DVT.

DVT is common health problem in Republic of Yemen. No previous studies have been carried out about this topic in this developing country. Therefore, this study intended to record the commonly affected veins in the anatomical map of the lower limbs. Compare the affected right and left lower limbs. Identify the relationship between DVT and gender. Assess various findings of CUS and Doppler in cases of DVT.

\section{Materials and Methods}

This study involved 46 cases of lower limb DVT. The data collected from the ultrasound Doppler reports of the patients who underwent lower limb imaging in the period from January 2017 to March 2018 at Ibb Scan Medical Diagnostic Center in Yemen. The study included all cases already diagnosed with DVT. Exclusion criteria involved all cases diagnosed with calf DVT and Cases of normal lower limb ultrasonography. Aboard-qualified radiologist with six years' experience in general ultrasound and Doppler imaging did all the ultrasound scans. A linear transducer of $7.5 \mathrm{MHz}$ of Medison-UGEO-H60 ultrasound machine was used in the imaging of all patients. 
Ethics: Institutional ethical approval for this study obtained from the head of the committee of Ibb Scan Medical Diagnostic Center. Confidentiality of the patient's information was assured during data collection.

The technique of examination: The common femoral vein (CFV), superficial femoral vein (SFV), the visible part of the deep femoral vein (DFV) and popliteal vein (Pop. V.) were optimally imaged using the gray-scale compression ultrasonography (CUS).

Venous compression was applied in the axial scans every $2 \mathrm{~cm}$ with adequate pressure to obliterate the healthy veins. Color and spectral Doppler were used to confirm the presence or absence of blood flow or DVT [7].

Statistical analysis: The collected data analyzed by using the SPSS "Statistical Package for the Social Sciences”, version 16. Chi-square test, Odds ratio (OR) and $95 \%$ confidence interval (95\% CI) were performed. Descriptive statistics were reported using frequencies and percentages.

\section{Results}

Out of 46 patients diagnosed with lower limb DVT, ages range was from 14 to 70 years. Females were affected more than male (71.74\% vs. $28.26 \%)$ (Table 1$)$. Left lower limb affected in $65.22 \%$ of cases, $28.26 \%$ in the right and $6.52 \%$ bilateral (Table 2 and Figure 1). Common femoral vein (CFV) and superficial femoral vein (SFV) affected in $71.7 \%$ of cases, popliteal vein affected in $67.4 \%$ and deep femoral vein affected only in $17.4 \%$ (Table 3). Both CFV and SFV affected together in $47.8 \%$ of cases. Both SFV and popliteal vein affected together in $50 \%$ of cases. Majority of DVT cases were in the acute stage (71.1\%), 17.4\% chronic and $6.5 \%$ patients acute on chronic stage (Table 4). Distension of the affected veins and absent blood flow were the predominant imaging features in acute stage rather than chronic $(\mathrm{p}<0.001)$ (Table 5 and Table 6$)$. Thickened wall of the affected vein was the predominant features in chronic stage $(\mathrm{p}<0.001)$ (Table 7). No significant relationship between gender and the affected side $(p=0.458)$. No significant association detected between loss of the typical compressibility of the veins and stage of DVT $(\mathrm{p}=0.115)$.

\section{Discussion}

This study was interested in recording the common locations of DVT in the lower limbs. Compression ultrasonography (CUS) with color and spectral Doppler were done to confirm the diagnosis and evaluate the locations of lower limb DVT in the patients who presented with suggesting clinical signs. The study revealed a wide variety of anatomical sites of DVT either in the affected side and segments.

There was a significant predominance of DVT in the left lower limb. This result was similar to a previous study by Kakale et al., who reported that proximal lower limb DVTs affected the left lower limb more than the right (14 vs. 6 cases) [8]. In a similar previous study by Chen et al., there was significant predominance of left lower limb than right (582 vs. 158) [9]. This result was also consistent with 
Table 1. Gender distribution of DVT.

\begin{tabular}{ccc}
\hline Gender & Number & Percent \\
\hline Male & 13 & $28.26 \%$ \\
Female & 33 & $71.74 \%$ \\
Total & 46 & $100 \%$ \\
\hline
\end{tabular}

Table revealed a significant tendency of DVT to affect female $(\mathrm{p}=0.003)$.

Table 2. Distribution of DVT in the right and left lower limbs.

\begin{tabular}{ccc}
\hline Site of DVT & Number of cases & Percent \\
\hline Left lower limb & 30 & $65.22 \%$ \\
Right lower limb & 13 & $28.26 \%$ \\
Bilateral & 3 & $6.52 \%$ \\
Total & 46 & $100 \%$
\end{tabular}

Table revealed a high tendency of DVT to affect left lower limb $(\mathrm{p}<0.001)$.

Table 3. Distribution of DVT in the venous segments of the lower limbs.

\begin{tabular}{ccccc}
\hline Site of DVT & CFV & SFV & DFV & Popliteal v. \\
\hline Affected segment & $33(71.7 \%)$ & $33(71.7 \%)$ & $8(17.4 \%)$ & $31(67.4 \%)$ \\
Not affected & $13(28.3 \%)$ & $13(28.3 \%)$ & $38(82.6 \%)$ & $15(32.6 \%)$ \\
Total & $46(100 \%)$ & $46(100 \%)$ & $46(100 \%)$ & $46(100 \%)$ \\
\hline
\end{tabular}

CFV \& SFV are the most common affected segments then popliteal vein.

Table 4. Distribution of DVT in different stages.

\begin{tabular}{ccc}
\hline Stage of DVT & Number & Percent \\
\hline Acute & 35 & $76.1 \%$ \\
Chronic & 8 & $17.4 \%$ \\
Acute on chronic & 3 & $6.5 \%$ \\
Total & 46 & $100 \%$ \\
\hline
\end{tabular}

Table revealed a significant tendency of DVT to be detected in acute stage $(\mathrm{p}<0.001)$.

Table 5. Correlation between distension of vein and stage of DVT.

\begin{tabular}{cccc}
\hline \multirow{2}{*}{ Sign } & \multicolumn{2}{c}{ Stage of DVT } & Total \\
\cline { 2 - 3 } & $31(91.2 \%)$ & Chronic & $34(100 \%)$ \\
Dilatation of vein & $4(33.3 \%)$ & $8(8.8 \%)$ & $12(100 \%)$ \\
No dilatation & $35(76.1 \%)$ & $11(23.9 \%)$ & $46(100 \%)$ \\
\hline
\end{tabular}

Table revealed an essential relationship between distension of vein and acute stage of DVT $(\mathrm{p}<0.001)(\mathrm{OR}$ 20.667, 95\% CI 3.826 - 111.633). 
Table 6. Correlation between absent venous flow and stage of DVT.

\begin{tabular}{cccc}
\hline \multirow{2}{*}{ Sign } & \multicolumn{2}{c}{ Stage of DVT } & \multirow{2}{*}{ Total } \\
\cline { 2 - 3 } & Acute & Chronic & \\
\hline Absent venous flow & $34(91.9 \%)$ & $3(8.1 \%)$ & $37(100 \%)$ \\
Normal venous flow & $1(11.1 \%)$ & $8(88.9 \%)$ & $9(100 \%)$ \\
Total & $35(76.1 \%)$ & $11(23.9 \%)$ & $46(100 \%)$ \\
\hline
\end{tabular}

Table revealed an essential relationship between absence of blood flow and acute stage of DVT $(\mathrm{p}<0.001)$ (OR 90.667, 95\% CI 8.303 - 990.114).

Table 7. Correlation between the thickened wall of vein and stage of DVT.

\begin{tabular}{cccc}
\hline \multirow{2}{*}{ Sign } & \multicolumn{2}{c}{ Stage of DVT } & \multirow{2}{*}{ Total } \\
\cline { 2 - 3 } & Acute & Chronic & \\
\hline Thickened wall & $0(0.0 \%)$ & $5(100 \%)$ & $5(100 \%)$ \\
No thickening & $35(85.4 \%)$ & $6(14.6 \%)$ & $41(100 \%)$ \\
Total & $35(76.1 \%)$ & $11(23.9 \%)$ & $46(100 \%)$ \\
\hline
\end{tabular}

Table revealed an essential relationship between absence of blood flow and chronic stage of DVT ( $\mathrm{p}<$ 0.001) (OR 6.833, 95\% CI 3.263 - 14.312).

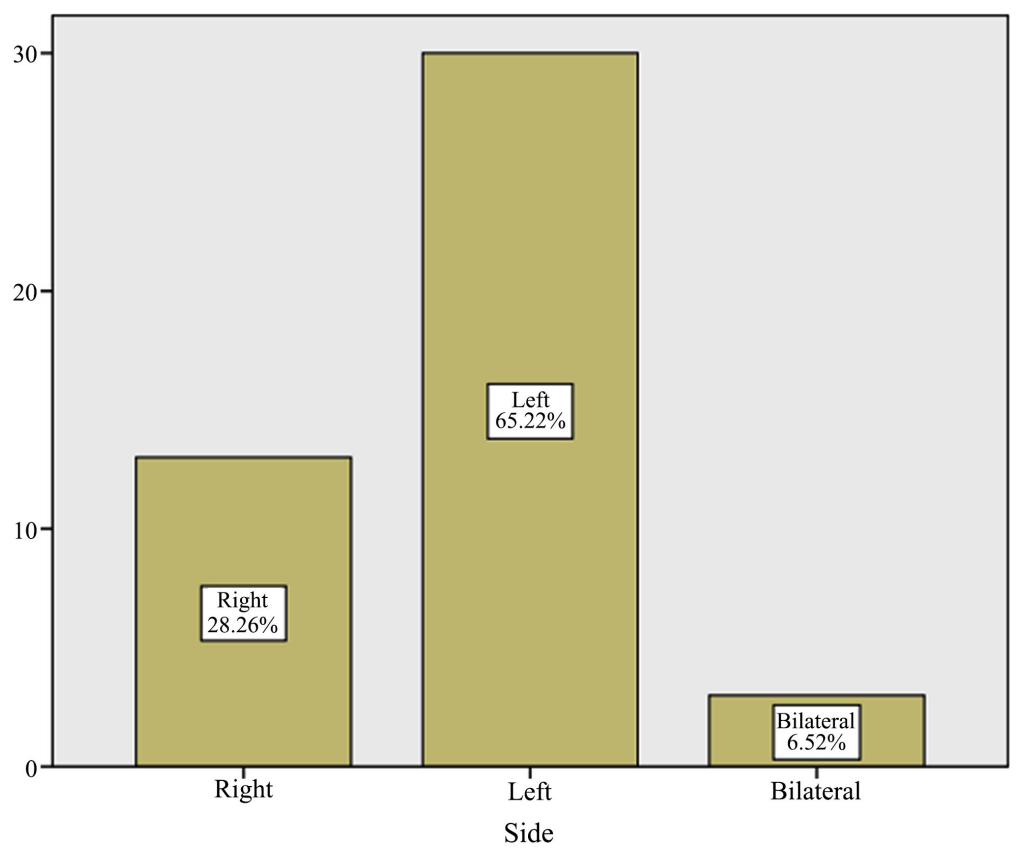

Figure 1. Distribution of DVT in the sides.

a previous study by Shin et al., who reported left sided predominance of lower limb DVT especially in women (74.2\%) [10]. No obvious explanation for the predominance of DVT in the left lower limb apart from the May-Thurner syndrome in which the right common iliac artery (CIA) overlies and compresses the left common iliac vein (CIV) against the lumbar spine due to an anatomical variant occurs in over $20 \%$ of population [11]. 
CFV and SFV were the most commonly affected veins by DVT in this study. This result was also compatible with a previous study by Khaladkar et al., who reported the predominant distribution of DVT in the SFV (88.5\%) than popliteal vein (69.2\%) [12]. This also was compatible with the results of De Maeseneer et al., who reported that SFV was the most commonly affected veins (58\%) than popliteal vein (56\%) [13]. The results were also similar to a previous study by Pomero et al., who found that DVT affects femoral veins more than popliteal [14].

The results of this study revealed a high predominance of DVT in females compared to males. This result was compatible with Hong et al., who reported the higher incidence of DVT in women [15]. This significant difference is explained by the presence of a lot of specific risk factors in females such as pregnancy, puerperium and hormone therapy such as OCPs.

Acute DVT reported in $76.1 \%$ of cases in this study. This result is compatible with a previous similar survey by Olowoyeye et al., who stated that acute DVT was the most frequent (58\%) lesion detected in patients with clinically suspected DVT [16].

In the current study, distension of the affected vein and absent blood flow were the predominating signs in the acute stage of DVT whereas thickened wall of veins was the predominant sign of chronic DVT. These findings were consistent with Karande et al., who reported that distension of vein by hypoechoic thrombotic material and absent blood flow are signs of acute DVT. Narrowing of the vein with wall thickening due to echogenic thrombus attached to it and positive blood flow due to thrombotic recanalization and development of collaterals are signs of chronic DVT. Complete or partial loss of normal venous compressibility is a sign in both acute and chronic DVT [17]. The absence of venous blood flow is a predominant finding in acute stage of DVT but not in chronic. This finding is explained by the high rate of recanalization in chronic DVT as reported by Brandão et al. [18].

\section{Limitations of This Study}

This study is limited in that; it was interesting small analysis of DVT in a single center in Yemen. The assessment of DVT was performed using Doppler ultrasonography, even though this technique does not provide accurate assessment for DVT of calf vein. Venography, which could be used for more accurate diagnosis of calf veins DVT, was not available. This study was retrospective with no available clinical data about the cause, management and follow up of the patients.

\section{Conclusion}

Lower limb deep venous thrombosis affects left lower limb more than the right and females more than males. Superficial femoral vein usually affected with the common femoral vein or popliteal vein. Lower limb DVT predominantly present in acute stage by venous distension and absent blood flow. 


\section{Disclosures}

The authors declare no conflict of interest.

\section{Financial Support}

None.

\section{Conflicts of Interest}

The authors declare no conflicts of interest regarding the publication of this paper.

\section{References}

[1] Min, S.-K., Kim, Y.H., Joh, J.H., Kang, J.M., Park, U.J., Kim, H.-K., et al. (2016) Diagnosis and Treatment of Lower Extremity Deep Vein Thrombosis: Korean Practice Guidelines. Vascular Specialist International, 32, 77-104. https://doi.org/10.5758/vsi.2016.32.3.77

[2] Brækkan, S.K., Grosse, S.D., Okoroh, E.M., Tsai, J., Cannegieter, S.C., Naess, I.A., et al. (2016) Venous Thromboembolism and Subsequent Permanent Work-Related Disability. Journal of Thrombosis and Haemostasis, 14, 1978-1987. https://doi.org/10.1111/jth.13411

[3] Vincentelli, G.M., Timpone, S., Murdolo, G., Fusco Moffa, I., L’Angiocola, P.D., Borgognoni, F., et al. (2018) A New Risk Assessment Model for the Stratification of the Thromboembolism Risk in Medical Patients: The TEVere Score. Minerva Medica, 109, 436-442. https://doi.org/10.23736/S0026-4806.18.05689-6

[4] Baker, M. and dela Cruz, J. (2018) Deep Venous Thrombosis, Ultrasound. StatPearls Publishing, Treasure Island, FL. https://www.ncbi.nlm.nih.gov/books/NBK470453

[5] Needleman, L., Cronan, J., Lilly, M., Merli, G.J., Adhikari, S., Hertzberg, B.S., et al. (2018) Ultrasound for Lower Extremity Deep Venous Thrombosis: Multidisciplinary Recommendations from the Society of Radiologists in Ultrasound Consensus Conference. Circulation, 137, 1505-1515. https://doi.org/10.1161/CIRCULATIONAHA.117.030687

[6] Zuker-Herman, R., Ayalon Dangur, I., Berant, R., Sitt, E.C., Baskin, L., Shaya, Y., et al. (2018) Comparison between Two-Point and Three-Point Compression Ultrasound for the Diagnosis of Deep Vein Thrombosis. Journal of Thrombosis and Thrombolysis, 45, 99-105. https://doi.org/10.1007/s11239-017-1595-9

[7] American College of Radiology (ACR), American Institute of Ultrasound in Medicine (AIUM) and Society of Radiologists in Ultrasound (SRU) (2015) Practice Guideline for the Performance of Peripheral Venous Ultrasound Examinations. Journal of Ultrasound in Medicine, 30, 143-150.

[8] Kakale, S.B., Maaji, S.M. and Aliyu, S.A. (2016) Lower Extremities Duplex-Doppler Ultrasonography for the Detection of Suspected Deep Venous Thrombosis: A Preliminary Report from Sokoto. Asian Journal of Medical Sciences, 7, 53-57. https://doi.org/10.3126/ajms.v7i6.14489

[9] Chen, F., Xiong, J.X. and Zhou, W.M. (2015) Differences in Limb, Age and Sex of Chinese Deep Vein Thrombosis Patients. Phlebology, 30, 242-248.

https://doi.org/10.1177/0268355514524192

[10] Shin, H.S. and Park, J.K. (2014) The Laterality of Deep Vein Thrombosis in the Pel- 
vic and Lower Extremity Veins. Vascular Specialist International, 30, 56-61. https://doi.org/10.5758/vsi.2014.30.2.56

[11] Peters, M., Syed, R.K., Katz, M., Moscona, J., Press, C., Nijjar, V., et al. (2012) May-Thurner Syndrome: A Not So Uncommon Cause of a Common Condition. Baylor University Medical Center Proceedings, 25, 231-233. https://doi.org/10.1080/08998280.2012.11928834

[12] Khaladkar, S.M., Thakkar, D.K., Shinde, K., Thakkar, D.K., Shrotri, H. and Kulkarni, V.M. (2014) Deep Vein Thrombosis of the Lower Limbs: A Retrospective Analysis of Doppler Ultrasound Findings. Medical Journal of Dr. D.Y. Patil Vidyapeeth, 7, 612-619. https://doi.org/10.4103/0975-2870.140449

[13] De Maeseneer, M.G.R., Bochanen, N., van Rooijen, G. and Neglén, P. (2016) Analysis of 1,338 Patients with Acute Lower Limb Deep Venous Thrombosis (DVT) Supports the Inadequacy of the Term "Proximal DVT". European Journal of Vascular and Endovascular Surgery. The Official Journal of the European Society for Vascular Surgery, 51, 415-420. https://doi.org/10.1016/j.ejvs.2015.11.001

[14] Pomero, F., Brignone, C., Serraino, C., Panzone, S., Bracco, C., Migliore, E., et al. (2011) Venous Lower-Limb Evaluation in Patients with Acute Pulmonary Embolism. Southern Medical Journal, 104, 405-411. https://doi.org/10.1097/SMJ.0b013e318213d037

[15] Hong, J., Lee, J.H., Yhim, H.-Y., Choi, W.-I., Bang, S.-M., Lee, H., et al. (2018) Incidence of Venous Thromboembolism in Korea from 2009 to 2013. PLoS ONE, 13, e0191897. https://doi.org/10.1371/journal.pone.0191897

[16] Olowoyeye, O.A., Awosanya, G.O. and Soyebi, K.O. (2010) Duplex Ultrasonographic Findings in Patients with Suspected DV T. The Nigerian Postgraduate Medical Journal, 17, 128-132.

[17] Karande, G.Y., Hedgire, S.S., Sanchez, Y., Baliyan, V., Mishra, V., Ganguli, S., et al. (2016) Advanced Imaging in Acute and Chronic Deep Vein Thrombosis. Cardiovascular Diagnosis and Therapy, 6, 493-507. https://doi.org/10.21037/cdt.2016.12.06

[18] Brandão, G.M., Sobreira, M.L., Malgor, R.D. and Rollo, H.A. (2014) Recanalization Rates after Acute Deep Vein Thrombosis: A Single-Center Experience Using a Newly Proposed Vein Diameter Variation Index. Annals of Vascular Surgery, 28, 1751-1760. https://doi.org/10.1016/j.avsg.2014.05.013 